\title{
The Impact of Real Estate Policies on the Housing Price in Major Cities in China
}

\author{
Wenjun Lyu, Chunyi Bu* \\ School of Economics \\ Shanghai University \\ Shanghai, China \\ lwj@shu.edu.cn, buchunyi96826@163.com*
}

\begin{abstract}
This paper used the panel data from August 2015 to March 2018 to analyze the effect of the policies - such as purchase restriction policy, loan restriction policy, sales restriction policy, price restriction policy and rent and purchase system - in the past two years on the housing price in major cities of China by establishing regression models. We found purchase restriction policy and price restriction policy can effectively restrain the growth of the housing price in the short term, but in the long run, they will lead to the retaliatory growth on price. Sales restriction policy has a significant impact on the housing price in the long run and it can lower the price. Rent and purchase system makes a limited effect on the price. All the policies should be combined together and be reasonable so as to stabilize the real estate market.
\end{abstract}

Keywords-The housing price; Restrcition policy; Real estate market; Regression models

\section{INTRODUCTION}

In order to restrain the rapid rise of real estate prices and prevent the overheating of the real estate economy resulting in a real estate bubble, the state has taken a series of regulatory measures to suppress house prices. However, the housing price is still high, especially in the first and second tier cities. Therefore, the government has introduced a series of shortterm and long-term policies according to each city from points and surfaces to stabilize house prices and strictly regulate the real estate market.

Xiaoman Li (2017) carried on the thorough research to the direct real estate control policy, combined with regression models, drawing the conclusion that the provident fund policy and purchase restriction policy have a significant effect on the real estate price fluctuation, while the indemnificatory apartment policy and the down payment ratio policy are not satisfactory [1].

Wenwen Zhou, Chao Liu and Xiao Li (2017) established the ARDL model of the housing price and real estate regulation and control policy, drawing the conclusions that in the short term, the effect of rental with right policy is not significant while purchase restriction policy shows significant effect on restraining the housing price. In the long run, rental with right policy has a long-term stable effect on the real estate [2].

This paper uses the panel data from August 2015 to March 2018 to analyze the effect of the policies - such as purchase restriction policy, loan restriction policy, sales restriction policy, price restriction policy and rent and purchase system in the past two years on the housing price in major cities of China by establishing regression models.

\section{THE INFLUENCE FACTORS ON HOUSING PRICE}

At present, the policy of house price regulation has completed a great turning from adjusting to controlling, mainly to stabilize the housing price of the first and second tier cities, so as to reconstruct the order of the real estate market by using the short-term restriction policy and the long-term mechanism. From the perspective of the short-term regulation on residential housing, the current control measures are given priority to purchase restriction policy and loan restriction policy, supplemented by sales restriction policy and followed by price restriction policy. In the long run, the policies are aimed at establishing a sound long-term mechanism by developing the rental market with rent and purchase system.

\section{A. Purchase Restriction Policy}

Purchase restriction policy refers to the policy that the government restrains the demand of housing directly by restricting the number of house purchased. Up to the end of 2017, a total of two rounds of purchase restriction policy have been implemented. By the end of 2017, more than 50 cities had joined the list of the purchase restriction, surpassing the first round.

The impact of purchase restriction policy on the housing price mainly lies in the short-term demand-side control. In particular, the restrictions can be divided into two types: the household registration restriction and the regional purchase restriction. The former restricts the purchase qualification of non-household population to purchase housing, and ensures the housing demand of the household registered population; The latter limits the number of housing units purchased in the main urban areas of the city in order to reduce the housing price in the city center. Purchase restriction policy is limiting the speculative buyers. As a result, those who can afford to buy more than two sets of residences are disqualified, which may lead to a fall in the housing demand and also in the price. To a certain extent, it can protect those who are qualified but temporarily inadequate in capacity to buy the house.

But in the long run, purchasers in the real estate market have enough time to adjust and change their purchasing behavior according to their own interests, such as using fake 
divorces to increase their qualification for purchase. Others may turn real estate investment from restricted cities to unfettered cities, leading to the potential of driving the housing price in other cities. When the market is depressed, the policy will be unbound. It makes the purchase restriction policy as weak as a blow just like 'a paper tiger'. As a result, 'the possibility of a retaliatory increase in housing price will appear rather than reducing it' [3].

\section{B. Loan Restriction Policy}

Loan restriction policy is a direct policy to curb the demand for housing by restricting the amount of loans to housing. The down payment ratio of the second house raised to 50\% In 2010, then raised it again to $60 \%$ later and adjusted the loan interest rate to 1.1 times of the benchmark interest rate in January 2011. Loan restriction policy has been cooperating with the purchase restriction policy to restrain the bubble of the real estate market after 2010.

As with the purchase restriction policy, loan restriction policy also influences the price of housing by controlling the demand side in the short term. It has two forms: limiting loan interest rate and setting minimum loan down payment ratio. However, loan restriction policy restricts only those with limited ability to buy homes, and does not deter those who do not need a loan to pay the down payments, so the speculators with adequate capital will still have a high demand for housing. Therefore, the loan restriction policy needs to cooperate with the use of the purchase restriction policy, so as to achieve the purpose of comprehensive restrictions on housing purchasers.

\section{Sales Restriction Policy}

Sales restriction policy refers to the regulation policy of restricting the transfer period after obtaining the real estate certificate to restrain the house transfer. Generally speaking, it must complete 2-3 years before it can be sold. By the end of 2017 , more than 50 cities had restricted sales, with restriction transfer periods ranging from 2 to 10 years.

Firstly, sales restriction policy restrains the housing price from both the supply and the demand side of the real estate market. Secondly, sales restriction policy is the mandatory requirement for the redistribution of the housing after the completion of the transaction. This increases the circulation costs and investment risks of housing speculators, and erodes the liquidity of capital, reducing the profits from it.

'The main shock targets of this regulation are those speculators who expect to buy and sell houses in a short period of time to make high profits' [4], further eliminating investment demand. Once these speculators do not transfer homes in the short term, the housing supply will be greatly reduced and the volume of transactions will naturally decline, which will undoubtedly cool the housing price. In the medium and long term, sales restriction policy also plays a certain role. Since the period of retransfer is 2-3 years or even longer, it can control the rise of housing price in the medium and long term, so that the demand for purchasing housing is converted to the demand for renting housing. Thus it develops the housing rental market in our country, which lays the groundwork for the improvement of the rent and purchase system, and gives sufficient preparation period for the long-term mechanism.

\section{Price Restriction Policy}

Price restriction policy is a direct and explicit regulation to restrict the increasing and the upper limit of the commodity housing price. According to incomplete statistics, more than 30 cities have introduced the policy since 2016.

Price restriction policy is the most direct policy in these four regulation policies. The government directly imposes rigid regulations on the housing price, mainly to limit the real estate developers, hoping to decrease the housing price from the supply side. In the short term, it may be effective, but in the long run, such a strong price limit will cause a retaliatory rebound in the housing price, and may even lead to hidden rules in the real estate market, such as bundling-sale, high pricing fees, and so on. Once such price controls are too strict, real estate developers, as rational economic agents, will take advantage of their own interests to find another way to selling the houses, resulting in the situation that the real estate market becomes more and more out of control.

\section{E. Rent and Purchase System}

Establishing a sound long-term mechanism focuses on the development of the rental market, the encouragement of the rental consumption and the stabilization of the lease relationship, so it is necessary to launch rent and purchase system. The emphasis of rent and purchase system lies in the word rent, which means speeding up the construction of housing rental market and the structural reform of the supply side of the real estate market. Specifically, the system can be interpreted from the following two aspects:

1) Enrich the housing rental market and realize multiagent supply of housing: In August 2017, a pilot plan was issued for the construction of rental housing by using collective construction land, and decided that the first batch of pilot projects should be carried out in 13 large and mediumsized cities such as Beijing, Shanghai, Nanjing, Hangzhou, etc.

At present, there are private rental housing, public rental housing and long-rented apartments in the rental market. Most private rental housing is provided by investors who make use of their own vacant homes to earn rent, while public rental housing is cheap housing provided by the government. As for long-rented apartments, they are a new type of rental housing in recent years. With a large amount of population packing into the first and second tier cities, private rental houses can't meet people's demand for commodity. In order to solve the problem of scarcity of housing resources, the government and public institutions have launched public rental housing to fill the gap in the rental market. Public rental housing can meet the living needs of the majority of consumers with better protection of renter's rights, which is professional in tenancy. Furthermore, the long-rented apartments have been used by large organizations as middlemen to rent the private houses for a long period of time, or to directly build their own houses, decorating them and then sublet them to people in need, especially the white-collar, after providing property service. In order to develop a rich rental market, public rental housing and 
long-rented apartments will become two major trends, gradually replacing private rental housing to occupy the rental market in our country in the future. They provide the long-term rental service for the people in need of housing, guarantee the renters' living rights and interests on the basis of increasing the rental supply, and achieve the effect of multi-main body supply.

2) Develop the housing rental market and realize the rental with right policy: The rental with right policy refers to the same treatment for the residents of renting and buying houses through legislation, gradually realizing the equal rights of the basic public services such as education, medical treatment, etc. It is a supplement to the rental market, and the mechanism lies in the transfer of the value of ownership to the value of the right to use, in order to convert people's demand for buying a house into a demand for rent. In 2017, Guangzhou put forward the concept of rental with right for the first time and clearly put forward that eligible children of lessee could enter the school nearby.

The rental with right policy has a greater advantage than those rental housing. First of all, it reduces the gap between renters and buyers to a minimum, so it can increase people's rental preference. Secondly, it can reduce people's housing consumption burden, so they do not have to take pains to buy a house. Third, the rental with right policy has certain force of law, so that tenants' rights and interests can be fully protected.

Whether to develop the rental market of multi-agent supply or to carry out the rental with right policy, it is for the purpose of realizing the goal that people can live in housing, reducing the demand for housing purchase by expanding the supply of housing, and satisfying the demand for self-residential housing. If the rental market is to develop effectively in the long term, it must protect the legitimate rights and interests of the lessee, providing no less stability than the self-purchased house. Besides, it must improve policy support, enrich the variety of the rental market, and meet all kinds of housing needs with strict government management.

The rental market of our country has been in a relatively backward stage compared with foreign countries, because various laws and regulations are not perfect and the rights and interests of the renters cannot be well protected. So, there is still a long way to develop the housing rental market. In fact, although the development of the rental market is not essentially aimed at curbing house prices, in the long run, the establishment of a sound rental market will definitely promote the rational development of the real estate market and lower people's psychological expectations of the housing price. Finally, it can reduce house purchase panic and restrain speculation phenomenon, so as to stabilize the housing price.

\section{EMPIRICAL ANALYSIS}

In order to study the effects of various policies on the housing price in China at present, the panel data from August 2015 to March 2018 are selected to establish a regression model. In view of the lack of enough data, this paper selects 11 cities with relatively complete and representative data, namely Beijing, Shanghai, Guangzhou, Shenzhen, Chengdu, Hangzhou, Wuhan, Chongqing, Nanjing, Tianjin and Changsha.
The explained variable is the price of house price named LNY. The monthly price of residential house is selected and indexed to the value of sales price in August 2015. Because the price has a certain seasonal fluctuation trend, to ensure that the data conform to the actual economic significance and are easy to analyze, the seasonal adjustment is carried out, and the logarithm is taken to eliminate the possible heteroscedasticity.

Explanatory variables are divided into 6 parts as follows:

1) Purchase restriction policy takes the form of virtual variable, according to whether the policy is implemented or not, and the former is assigned to 1 , while the latter is assigned to 0 . We name the variable as $\mathrm{X}_{1}$.

2) We choose the average interest rate of the first house loan and the main down payment ratio of the second house as the explanatory variables of loan restriction policy, which are named as $\mathrm{X}_{2}$ and $\mathrm{X}_{3}$ respectively.

3) Sales restriction policy is explained by the terms of transfer after obtaining the real estate certificate, named by $\mathrm{X}_{4}$.

4) Finally, price restriction policy and rent and purchase system also take the form of virtual variables, according to whether the policy is implemented or not, and the variable is assigned to 1 if the policy is implemented, otherwise is assigned to 0 . We name the variable as $\mathrm{X}_{5}$ and $\mathrm{X}_{6}$ respectively.

The data above are from CRIES, WIND and some are arranged on the basis of the information issued by the network.

\section{A. Unit root test}

First of all, we need to test the stability of the panel data model before determining whether there is a long-term cointegration relationship between the explained variable and the explanatory variables.

According to the ADF unit root test results in Table I, the main down payment ratio of the second house is stable time series, while the other 6 variables are not, but they are all stable after the first order difference. Therefore, the variables after eliminating $\mathrm{X}_{3}$ can be tested by cointegration test.

TABLE I. THE RESULTS OF UNIT RoOT TEST

\begin{tabular}{|l|l|l|}
\hline \multicolumn{1}{|c|}{ Variable } & \multicolumn{1}{|c|}{ Statistic } & \multicolumn{1}{c|}{ P-value } \\
\hline $\mathrm{LNY}$ & 25.4042 & 0.2781 \\
\hline $\mathrm{X}_{1}$ & 5.0275 & 0.9571 \\
\hline $\mathrm{X}_{2}$ & 24.8058 & 0.3065 \\
\hline $\mathrm{X}_{3}$ & 278.2370 & 0.0000 \\
\hline $\mathrm{X}_{4}$ & 4.7756 & 0.9057 \\
\hline $\mathrm{X}_{5}$ & 5.5937 & 0.9757 \\
\hline $\mathrm{X}_{6}$ & 5.9424 & 0.9679 \\
\hline $\mathrm{D}(\mathrm{LNY})$ & 273.5590 & 0.0000 \\
\hline $\mathrm{D}\left(\mathrm{X}_{1}\right)$ & 87.4540 & 0.0000 \\
\hline $\mathrm{D}\left(\mathrm{X}_{2}\right)$ & 192.7580 & 0.0000 \\
\hline $\mathrm{D}\left(\mathrm{X}_{4}\right)$ & 75.7749 & 0.0000 \\
\hline $\mathrm{D}\left(\mathrm{X}_{5}\right)$ & 103.4820 & 0.0000 \\
\hline $\mathrm{D}\left(\mathrm{X}_{6}\right)$ & 105.5660 & 0.0000 \\
\hline
\end{tabular}




\section{B. Cointegration Test}

Then we use Kao Residual Cointegration Test based on the ADF unit root test to determine whether or not the model has the meaning of regression. Since the P-value is 0.043 , it indicates that there is a long-term equilibrium relationship between the explained variable and the explanatory variables by cointegration test, and the non-pseudo-regression equation can be established. Therefore, the regression model has statistical economic significance.

\section{Hausman Test}

After the cointegration test, the initial regression of the variable is first made. The conclusion is that $\mathrm{X}_{1}, \mathrm{X}_{4}, \mathrm{X}_{5}$ and $\mathrm{X}_{6}$ are significant, while $X_{2}$ is not significant, so we choose to eliminate $\mathrm{X}_{2}$ and re-establish the regression. Next, in order to further determine the best form of the regression equation, Hausman test is used to determine whether the model fits the fixed effects model or the random effects model. The empirical results show that the $\mathrm{P}$-value is 0.4592 , greater than 0.05 , so the original hypothesis is accepted and the random effect regression model should be established. According to the actual situation, there are a large number of cities in China. The selected cities are only part of a certain representative, which can be popularized to other first and second tier cities, so the selection of random effect model is reasonable.

\section{Long-term Equilibrium Regression Model}

The regression results are shown in Table II that the four explanatory variables are significant, and the adjusted $\mathrm{R}^{2}$ is 0.35 .

TABLE II.

THE REGRESSION RESULTS

\begin{tabular}{|l|l|l|l|}
\hline \multicolumn{1}{|c|}{ Variable } & \multicolumn{1}{c|}{ Coefficient } & \multicolumn{1}{c|}{ t-Statistic } & \multicolumn{1}{c|}{ P-value } \\
\hline $\mathrm{X}_{1}$ & 0.1534 & 10.8345 & $0.0000^{* * *}$ \\
\hline $\mathrm{X}_{4}$ & -0.0151 & -2.2825 & $0.0231 * *$ \\
\hline $\mathrm{X}_{5}$ & 0.0601 & 2.7571 & $0.0061 * * *$ \\
\hline $\mathrm{X}_{6}$ & 0.1011 & 4.9610 & $0.0000^{* * *}$ \\
\hline $\mathrm{C}$ & 4.6840 & 68.2440 & $0.0000^{* * *}$ \\
\hline
\end{tabular}

a. $* * *$ means significant at $1 \%,{ }^{* *}$ means significant at $5 \%,{ }^{*}$ means significant at $10 \%$, the same as

We can get the long-term equilibrium model as in (1):

$$
\begin{gathered}
\mathrm{LNY}_{\mathrm{i}, \mathrm{t}}=(0.1534) \mathrm{X}_{1, \mathrm{it}}+(-0.0151) \mathrm{X}_{4, \mathrm{it}}+ \\
(0.0601) \mathrm{X}_{5, \mathrm{it}}+(0.1011) \mathrm{X}_{6, \mathrm{it}}+4.6840+\mu_{\mathrm{it}}
\end{gathered}
$$

\section{E. Error Correction Model}

In order to enhance the accuracy of the model, we establish error correction model (ECM) to make up for the shortcomings of the long-term equilibrium regression model. In this case, the error in the long-term equilibrium regression model is regarded as the equilibrium error, and named it EC. Adding the lag period, the regression results obtained are shown in Table III.
In the error correction model, $\mathrm{X}_{4}$ is significant without lags, and $\mathrm{X}_{1}, \mathrm{X}_{5}, \mathrm{X}_{6}$ are significant with lag2, lag5 and lag1 respectively.

TABLE III. THE REGRESSION RESULTS OF THE ECM

\begin{tabular}{|l|l|l|l|}
\hline \multicolumn{1}{|c|}{ Variable } & \multicolumn{1}{c|}{ Coefficient } & \multicolumn{1}{c|}{ t-Statistic } & \multicolumn{1}{c|}{ P-value } \\
\hline $\mathrm{D}\left(\mathrm{X}_{1}\right)$ & 0.0266 & 1.7389 & 0.0830 \\
\hline $\mathrm{D}\left(\mathrm{X}_{1}(-2)\right)$ & -0.0286 & -3.2823 & $0.0011^{* * *}$ \\
\hline $\mathrm{D}\left(\mathrm{X}_{4}\right)$ & 0.0071 & 2.8015 & $0.0054^{* * *}$ \\
\hline $\mathrm{D}\left(\mathrm{X}_{5}\right)$ & 0.0202 & 0.4654 & 0.6419 \\
\hline $\mathrm{D}\left(\mathrm{X}_{5}(-5)\right)$ & -0.0245 & -2.4716 & $0.0140^{* *}$ \\
\hline $\mathrm{D}\left(\mathrm{X}_{6}\right)$ & -0.0093 & -0.8664 & 0.3869 \\
\hline $\mathrm{D}\left(\mathrm{X}_{6}(-1)\right)$ & -0.0370 & -5.3861 & $0.0000^{* * *}$ \\
\hline $\mathrm{EC}(-1)$ & -0.0638 & -2.7030 & $0.0072^{* * *}$ \\
\hline $\mathrm{C}$ & 0.0098 & 3.2546 & 0.0013 \\
\hline
\end{tabular}

\section{CONCLUSION}

In the short term, purchase restriction policy and price restriction policy will decline the housing price, but they play the role only when it is 2 months behind and 5 months behind respectively. While sales restriction policy will make the house price temporarily raise in the short term.

In the long run, purchase restriction policy and price restriction policy will cause the housing price to rise in revenge, and the retaliatory growth caused by purchase restriction policy is far more serious. The effect of loan restriction policy is not significant, because it needs to be implemented with other policies. However, sales restriction policy can restrain the rise of house prices and ease the bubble of the real estate market.

Contrary to expectations, rent and purchase system will warm up the housing price in the real estate market of our country. This is due to the fact that the proposal of the system is still short, and the rental market in China is still in the process of being perfected. Few cities have introduced the housing lease pilot and the rental with right policy. Therefore, the impact on housing price cannot be demonstrated from the empirical results. And to some extent, the long-effect mechanism is not aimed to curb the rise of house prices, but is to establish a sound real estate market, so that people can have house to live in and protect their right to live, thus pricking the bubble of the overheated real estate market.

\section{REFERENCES}

[1] W.W. Zhou, C. Liu, and J. Li, "Study on the impact of real estate policy regulation on housing prices: an analysis based on ARDL model," Price:Theory \& Practice, vol. 401(11), pp.70-73, 2017 (in chinese).

[2] X.M. Li, Research on the influence of direct regulation and control policy in real estate price fluctuation, Shandong University: China, 2017. (in chinese)

[3] X. Chen and X.Q. Zhao, "An empirical study on the effect of purchase restriction and loan restriction on house prices," Wuhan Finance, vol. 217(01), pp. 21-26, 2018 (in chinese)

[4] T.J. Zhong, "On the essence and effectiveness of housing sales restriction policy," Urban and Rural Development, vol. 529(22), pp. 6-9. 2017 (in chinese). 